\title{
Insulin signaling and limb-patterning: candidate pathways for the origin and evolutionary diversification of beetle 'horns'
}

\author{
DJ Emlen ${ }^{1}$, Q Szafran ${ }^{1}$, LS Corley ${ }^{2}$ and I Dworkin ${ }^{3}$ \\ ${ }^{1}$ Division of Biological Sciences, The University of Montana, Missoula, MT 59812, USA; ${ }^{2}$ Department of Entomology, Washington State \\ University, Pullman, WA 99164-6382, USA; ${ }^{3}$ Department of Genetics, North Carolina State University, Raleigh, NC 27695-7614, USA
}

\begin{abstract}
Beetle 'horns' are rigid outgrowths of the insect cuticle used as weapons in contests for access to mates. Relative to their body size, beetle horns can be enormous. They protrude from any of five different regions of the head or thorax; they are curved, straight, branched or bladed; and their development is often coupled with the nutrient environment (male dimorphism) or with sex (sexual dimorphism). Here, we show that this extraordinary diversity of horns can be distilled down to four trajectories of morphological change - horn location, shape, allometry and dimorphism - and we illustrate how the developmental mechanisms regulating horn growth could generate each of these types of horn evolution. Specifically, we review two developmental pathways known to regulate growth of morphological structures in Drosophila and other insects: a limb-patterning pathway that specifies the location and shape of a structure, and the insulin pathway, which
\end{abstract}

modulates trait growth in response to larval nutrition. We summarize preliminary evidence indicating that these pathways are associated with the development of beetle horns, and we show how subtle changes in the relative activities of these two pathways would be sufficient to generate most of the extant diversity of horn forms. Our objective is to intuitively connect genotype with phenotype, and to advocate an informed 'candidate gene' approach to studies of the developmental basis of evolution. We end by using this insight from development to offer a solution to the longstanding mystery of the scarabs: the observation by Darwin, Lameere, Arrow and others that this one family of beetles appeared to have a 'special tendency' towards the evolution of horns.

Heredity (2006) 97, 179-191. doi:10.1038/sj.hdy.6800868; published online 19 July 2006

Keywords: evo-devo; imaginal discs; limb-patterning; insulin; insulin-receptor; Scarabaeidae

\section{Introduction}

One of the most exciting outcomes of the field of evolutionary developmental biology has been the realization that in diverse taxa, phenotypes are constructed in remarkably similar ways (eg Hall, 1992; Raff, 1996; Gerhart and Kirschner, 1997; Carroll et al, 2001). Once biologists recognized that the location, timing and function of genes expressed in one laboratory model organism paralleled the expression of homologous genes in other model organisms, genetic studies of development became a lot more feasible for nonmodel organisms (Raff, 2000; Brakefield et al, 2003; Fitzpatrick et al, 2005). This conservation of developmental processes means that it is now possible to predict a priori which genes and gene interactions are likely to control developmental processes in almost any taxon. Designing primers that bind to conserved regions of a specific candidate gene, and using those primers to probe DNA samples collected from a previously unstudied species, permits researchers to amplify and clone

Correspondence: DJ Emlen, Division of Biological Sciences, 104 Health Science Building, The University of Montana, Missoula, MT 59812-1002, USA. E-mail: doug.emlen@mso.umt.edu

Received 1 November 2005; accepted 5 June 2006; published online 19 July 2006 that gene from the new species, to design species-specific primers for the gene, to measure locations and levels of expression of the gene, and even to begin to study the function of this gene by temporarily 'knocking down' transcript levels during development (reviewed in: Fitzpatrick et al, 2005). These approaches have brought comparative studies of animal development to a new level, and we now have information on the expression and function of important candidate genes from a wealth of animal taxa.

In this paper, we illustrate how this type of candidate gene approach can be used to study the development and evolution of a major morphological structure, beetle 'horns' (Figure 1). We briefly describe two developmental pathways known to be involved in the control of appendage growth in insects, and highlight elements of these pathways that function at the level of individual tissues to control the final sizes and shapes of adult morphological structures. We review recent evidence that these same pathways control the development of beetle horns, and show how studies of the expression and function of candidate genes in these pathways will permit us to reconstruct historical patterns of evolution of the developmental mechanisms regulating horn growth - a vital and exciting glimpse into the origin and evolutionary radiation of these exaggerated weapons of sexual selection. 


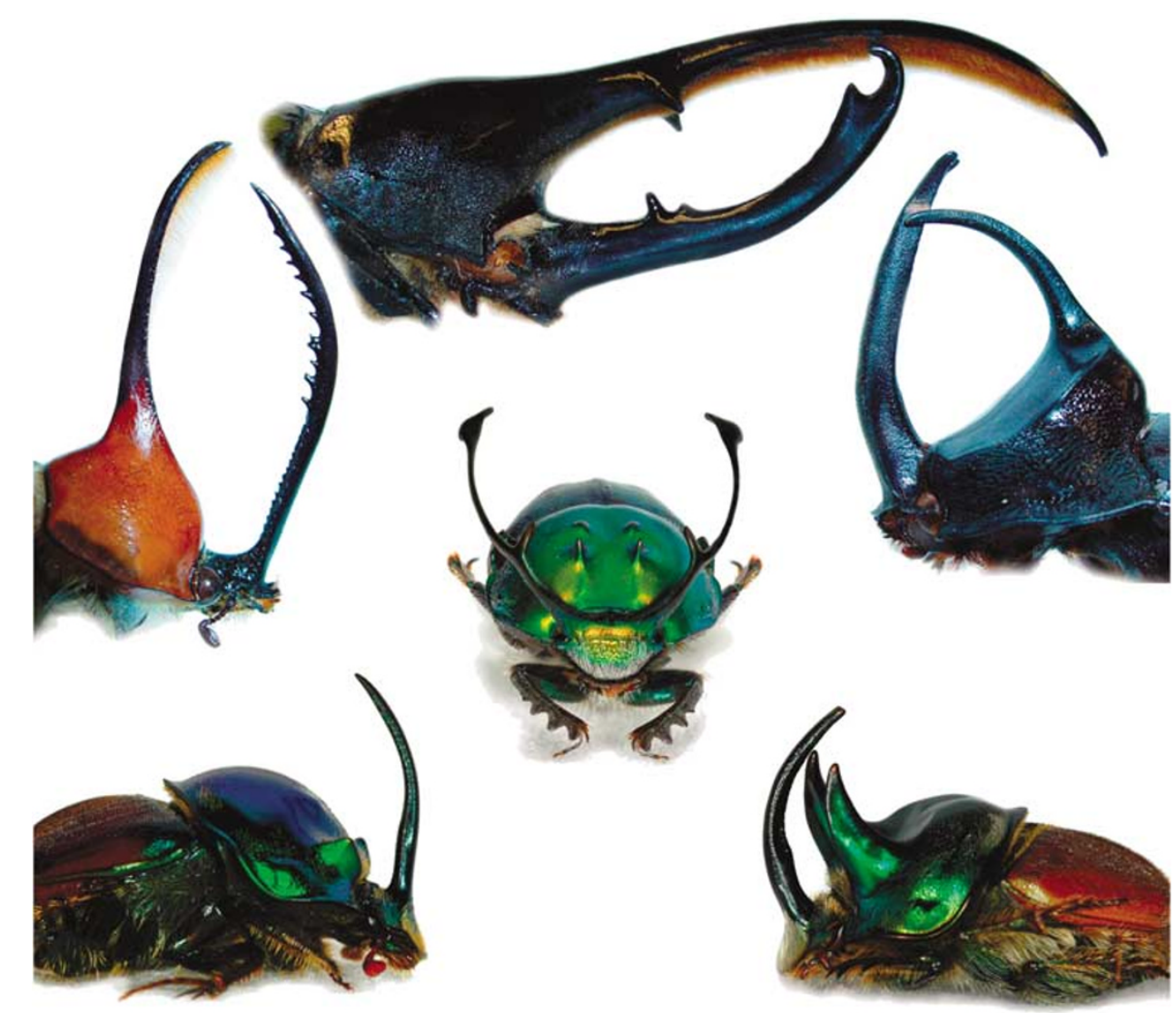

Figure 1 Scarab beetles with horns. Sample taxa illustrating the extreme size, and some of the shapes, of beetle horns: top: Dynastes hercules (Dynastinae); middle, left to right: Golofa porteri (Dynastinae); Onthophagus rangifer (Scarabaeinae); Enema pan (Dynastinae); bottom: Proagoderus tersidorsis (Scarabaeinae); Proagoderus lanista (Scarabaeinae). Photos: O Helmy, D Emlen.

\section{The horned beetles}

The fantastic shapes of beetles with horns have awed biologists for centuries (Drury, 1770; Fischer, 1823; Burmeister, 1847; Bates, 1863; Darwin, 1871; Paulian, 1935; Beebe, 1944; Arrow, 1951). Beetle horns are rigid outgrowths of the exoskeleton typically used in combat between males for access to resources used by females (eg Eberhard, 1978; Rasmussen, 1994; Emlen, 2000; Hunt and Simmons, 2001; Iguchi, 2001; Hongo, 2003; Figure 1). Although there are over 120 different families of beetle, and isolated representatives of many of these bear some form of cuticular outgrowth, the vast majority of horned species are concentrated within a single beetle family: the Scarabaeidae.

Thousands of scarab species bear horns (Arrow, 1951; Enrodi, 1985). The extreme sizes of these structures (Figure 1), and their concentration within one taxonomic family of beetles, has led naturalists since Darwin to reflect on the special nature of the Scarabs, noting both that sexual selection appears to have acted especially effectively in these beetles (Darwin, 1871, p. 377), and that they appeared to have a 'special tendency' to the acquisition of horns (Arrow, 1951, p. 94). What was it about the scarabs that predisposed so many lineages towards the evolution of these exaggerated weapons? Recent advances in our understanding of how insects develop, and in particular, of how beetle horns develop, are providing fresh new tools for addressing this and other long-standing questions of animal diversity and morphological evolution.

Horns appear to have arisen repeatedly within the scarabs (eg Arrow, 1951; Grimaldi and Engel, 2005), and in numerous lineages these structures have attained extreme proportions. Today, the geotrupids ('dor' beetles), the scarabaeids ('dung beetles') and the dynastines ('rhinoceros beetles') are predominated by species with exaggerated horns. Within each of these clades, horn morphologies are surprisingly evolutionarily labile (eg a recent phylogenetic analysis of 48 species from one scarab genus revealed 25 changes in the physical location of horns, and extensive interspecific variation in horn size and shape; Emlen et al, 2005b). A close examination of this variation suggests that in addition to gains or losses of horns, there have been four principle axes, or trajectories of horn evolution (Figure 2). Species differ in the physical location of their horns (eg head vs thorax, center vs sides of the thorax). Species differ in horn shape (straight, curved, branched, etc.). They also differ in horn allometry - a reflection both of the relative size of the horn, and of the developmental coupling of horn growth with among-individual variation in body size. Finally, species differ in the presence/absence, and the nature of dimorphism in horn expression, either male dimorphism (large $v s$ small males) and/or sexual dimorphism (males vs females).

Combined, these four trajectories of morphological change can account for much of the visible diversity in 

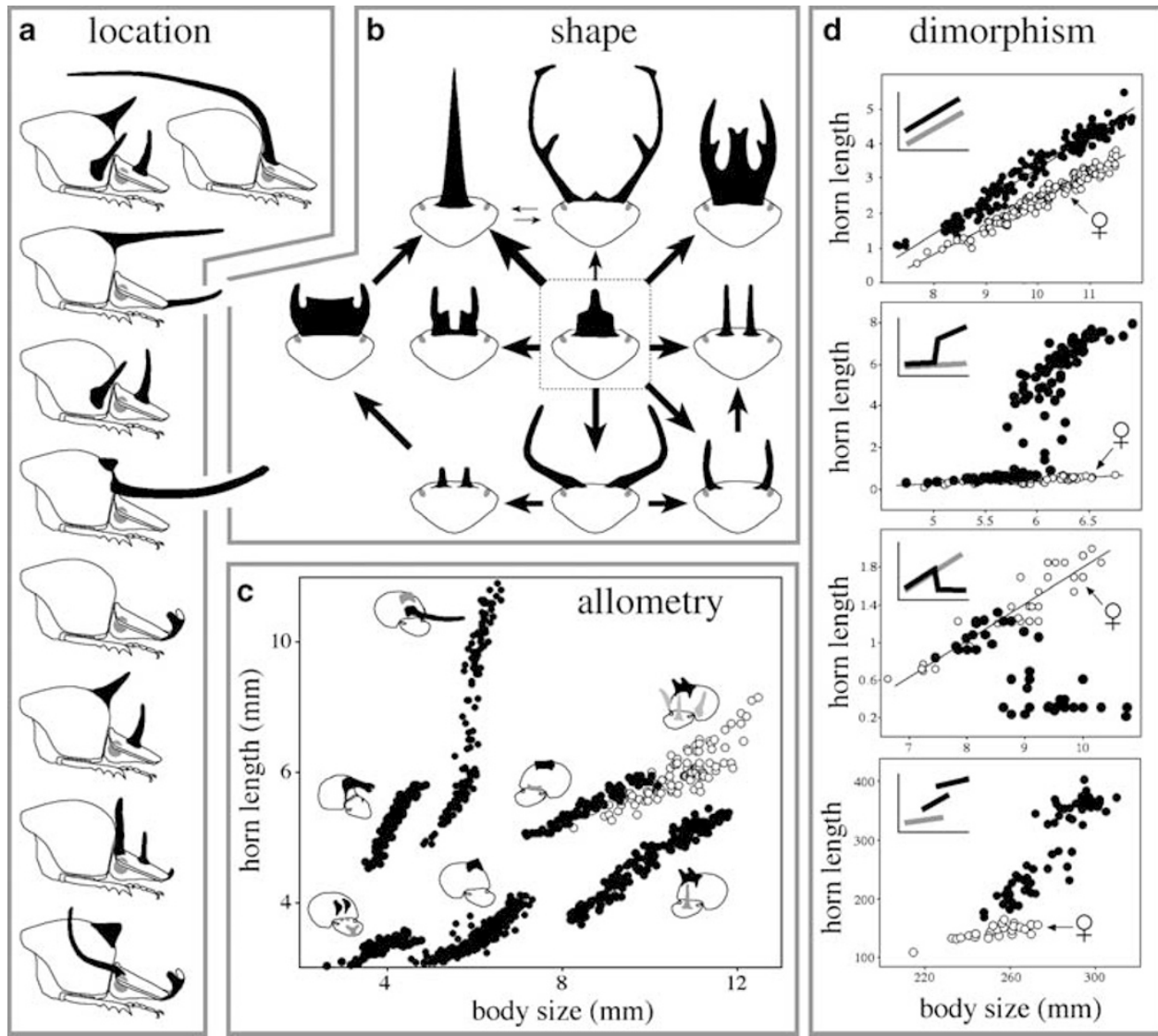

Figure 2 Four trajectories of beetle horn evolution. (a) Species differ in the location of horns; side-views of nine species of Onthophagus (Scarabaeinae) shown. (b) Species differ in horn shape. Head horns shown for 10 Onthophagus species; arrows indicate relative frequencies of changes as reconstructed from a phylogeny (from Emlen et al, 2005b). (c) Species differ in horn allometry, the slopes, intercepts, and even the shapes of the scaling relationships between horn length and body size. Data for thoracic horns of seven Onthophagus species shown. Finally, (d) species differ in the presence and nature of dimorphism in horn expression (males $=$ closed circles; females $=$ open circles). Top to bottom: sexual dimorphism (O. pentacanthus); male dimorphism and sexual dimorphism (O. nigriventris); reversed male \& sexual dimorphism (O. sloanei); male dimorphism and sexual dimorphism (Enema pan (Dynastinae); unpublished data, JM Rowland).

scarab horns. Categorizing these among-species patterns into biologically meaningful trajectories allows us to consider how these changes are generated - which physiological and developmental pathways are involved, and even which specific genes in these pathways are involved. Our long-term goal is to study the developmental mechanisms underlying all four of these trajectories in order to better understand the genetic bases for adaptive morphological evolution. In this paper, we summarize what is currently known about the developmental mechanisms regulating horn growth. Specifically, we describe two pathways now known to be involved with the control of horn development, and we illustrate why these are likely mechanisms for the evolutionary diversification of horn form.

\section{Development of beetle horns}

All scarab beetles undergo a complete metamorphosis during development: after three larval instars they molt into a pupa, and then subsequently into an adult. Once an individual has eclosed as an adult, they do not molt again, and their morphology is fixed for the remainder of their life.
Horns form during the larval period, from clusters of epidermal cells that detach from the larval cuticle and undergo a local burst of growth. In Onthophagus taurus, O. nigriventris and Xylotrupes gideon, the horns delay growth until very late in the larval period (the prepupa period; Figure 3). As animals purge their guts in preparation for metamorphosis, these epidermal cells begin a rapid burst of proliferation and form evaginated discs of densely folded tissue (horn discs) that unfurl to their full length when the animal sheds its larval cuticle and molts into a pupa (Emlen and Nijhout, 1999; Moczek and Nagy, 2005; Emlen et al, 2005a).

Several factors are thought to control the amount of proliferation that occurs in these developing horn discs, and thus the final size of the horns. First, these structures are highly phenotypically plastic: their development depends critically on larval access to nutrition (Emlen, 1994; Iguchi, 1998; Moczek and Emlen, 1999; Hunt and Simmons, 2000; Karino et al, 2004). Both horn size and body size are sensitive to variation in nutrition, and this results in a coupling of the amount of horn growth with overall body size (reflected in tight scaling relationships between horn length and body size, or allometry; Figure 2c). 

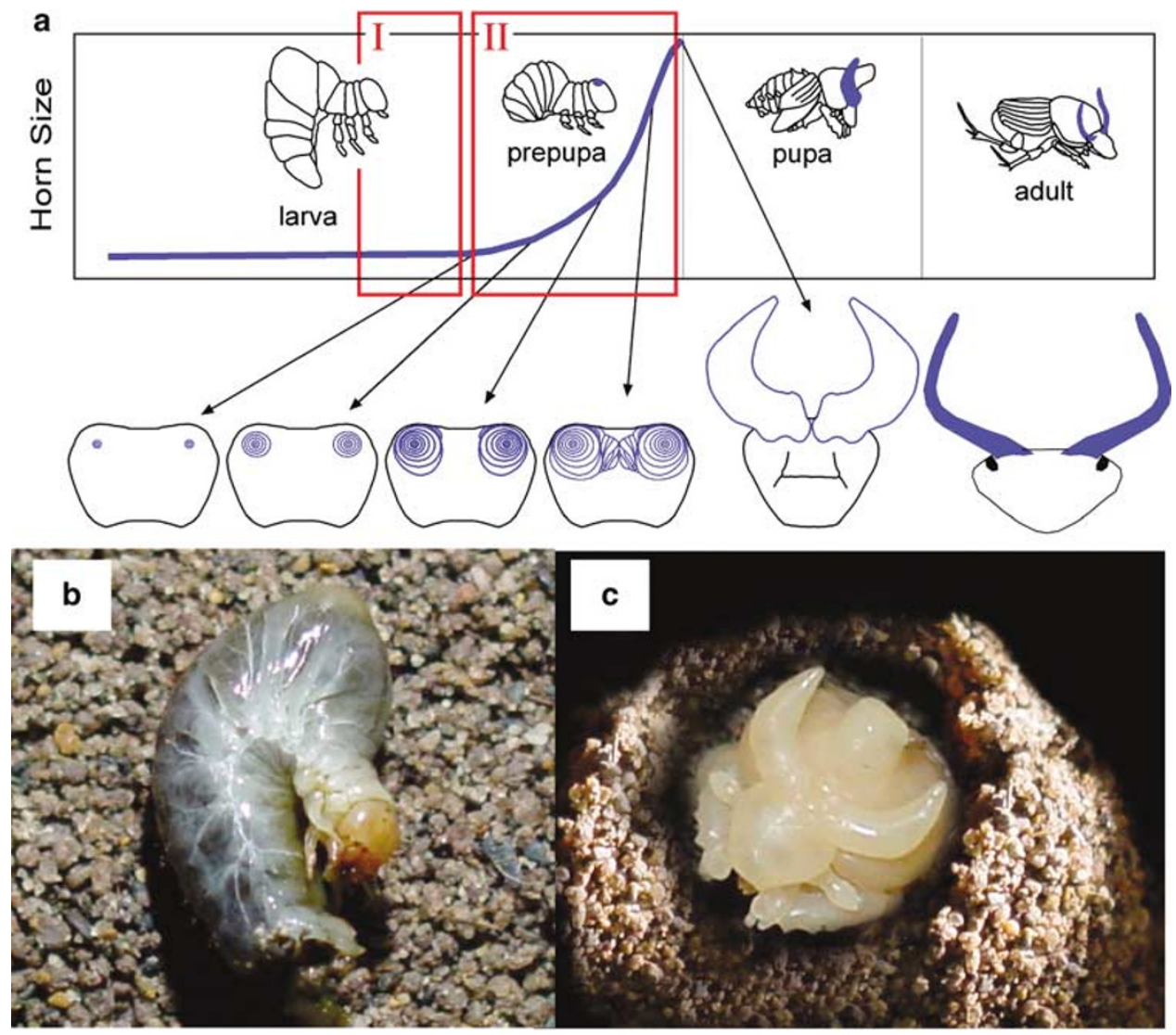

Figure 3 Development of beetle horns. (a) Horns form from clusters of epidermal cells (the horn disc) that undergo a localized burst of growth, ultimately producing a long evagination/outgrowth from the adult body. The cells that will form the horns begin proliferating near the end of the final (third) larval instar as animals stop feeding and purge their guts in preparation for metamorphosis (blue curve); horns have largely completed all growth by the end of the prepupa period. Horns at this stage comprise densely folded tubes of epidermis that unfurl as the animal sheds its larval cuticle. Third instar larva (b) and pupa (c) from O. taurus shown. Horn growth is known to be sensitive to endocrine signals during two critical periods: during the first (red box I) hormones appear to control the fate of horn cells (horn growth, no horn growth); during the second (red box II), they control the amount of horn growth. Considerable resorbtion of horn tissues can also occur in some individuals during the pupal period (eg in thoracic horns of females; see Moczek this issue).

Second, horn growth in many scarabs is also regulated by developmental 'switch' mechanisms (sensu WestEberhard, 2003) that either truncate, or otherwise alter patterns of horn growth in specific subsets of individuals (Figure 2d). Females, for example, often do not produce horns irrespective of their nutritional environment or body size (sexual dimorphism). Similarly, males smaller than a threshold body size also often do not produce horns, resulting in horn lengths that scale very differently with body size from those of large males (male dimorphism). Unlike the mechanism of allometry, which modulates the growth of most adult traits in beetles, the mechanisms of dimorphism appear to affect only the growth of the horns.

Finally, a network of local gene interactions unfolds within the developing horn disc itself, specifying the shape and the approximate final size of the horn (the limb-patterning pathway). This pathway must interact with the physiological signaling mechanisms of allometry and dimorphism to coordinate the total amount of growth of a horn; although to our knowledge, how these mechanisms interact has yet to be investigated for any insect.

Initial studies of the endocrine regulation of horn growth in $O$. taurus focused on the dimorphic switches between horned and hornless patterns of development (eg Emlen and Nijhout, 1999; Emlen and Nijhout, 2001; Moczek and Nijhout, 2002), and identified two critical windows during the third (final) larval stage when hormones appeared to influence the growth of horns (Figure 3). Current models suggest that interactions between the steroid hormone ecdysone and the terpenoid juvenile hormone $(\mathrm{JH})$ control the fate of horn cells (growth permitted, growth suppressed) during a first critical period that occurs near the end of larval feeding, just prior to the gut purge (Period I). These endocrine events have been described in detail elsewhere (Emlen and Nijhout, 2001; Moczek and Nijhout, 2002; Emlen et al, 2005a; see also Moczek, this issue), and we do not discuss them further here.

This paper focuses on a second critical period when horn cells are again sensitive to hormone levels (Period II): the period of horn growth. Animals have stopped feeding by this time, and the horns, wings, genitalia, and other appendage primordia undergo rapid proliferation. This is when the rate of trait growth is likely to be modulated in response to insulin or other circulating signals (eg in Drosophila: Mirth et al, 2005; Shingleton et al, 2005); this is when the outgrowth axis of horn discs is patterned (Moczek and Nagy, 2005); and this is when 
either or both of these processes may be altered in the horn discs of small males and females, to repress horn growth.

\section{The limb-patterning pathway and the evolution of horn location and shape}

Insect imaginal discs are remarkably autonomous entities analogous in many ways to the limb buds of vertebrates (Panganiban et al, 1997; Shubin et al, 1997; Kojima, 2004; Weihe et al, 2005). For this paper, we use the term 'imaginal discs' to refer broadly to insect appendage primordia, clusters of epithelial cells that form an axis of outgrowth, and whose proliferation is regulated at least partially independently from surrounding cells. This usage emphasizes shared properties of the development of these tissues, irrespective of whether they form as invaginations or evaginations, or whether they begin proliferating early (eg Drosophila wings, beetle legs) or late (eg butterfly eyes, beetle wings). See Svacha (1992) and Truman and Riddiford (2002) for more precise definitions and for an evolutionary context that places the highly derived (and atypical) discs of Drosophila within the broader milieu of insect appendage primordia).

It has been known for decades that discs could be surgically removed and transplanted to other body segments, or even to other individuals, without altering the identity or form of the structure produced by the disc (eg a leg disc still grows to become a leg; Kopec, 1922; Pohley, 1965; Hadorn, 1966). Similarly, small pieces of a disc could be excised, and the surrounding cells would spontaneously begin proliferating and the missing region would be regenerated (eg Simpson et al, 1980; O'Brochta and Bryant, 1987; Gibson and Schubiger, 1999). It was as if the disc itself contained the complete set of instructions needed to form an entire adult structure. In fact, this is precisely what happens, and some of the most impressive recent advances in the field of insect developmental genetics have focused on elucidating just how this process works (reviewed in Serrano and O'Farrell, 1997; Held, 2002; Johnston and Gallant, 2002; Kojima, 2004; Weihe et al, 2005).

In Drosophila, the epithelial cells within each of the imaginal discs begin as a relatively undifferentiated sheet of cells, but discs become increasingly subdivided by a hierarchical sequence of spatially explicit signals that diffuse from cell to cell. Partially overlapping gradients of these signals create a mosaic of molecularly distinct regions, or domains, within the disc epithelium, and interactions between these signals (eg at the intersections of signal domains) initiate and coordinate subsequent patterns of gene expression and cell behavior. The result is a cascade of nested genetic interactions that is largely self-contained within the disc epithelium, so that each tier of gene expression is sufficient to induce the next. By the end of this process, the formerly uniform field of cells now has a very explicit pattern - a precise spatial map defined by the overlapping gradients of these different molecular signals.

The disc will not look like the final structure until it unfolds, an event that happens as the animal pupates. But by this stage all of the parts of the structure are in place: cells in dorsal regions can be distinguished from those in ventral regions, anterior is distinguishable from posterior, and, importantly, there is an axis of outgrowth - a distal tip to the structure that, once unfolded, will lie well outward from the rest of the body.

Figure 4 illustrates a portion of the limb-patterning pathway, highlighting genes and interactions involved with localizing the distal tip of a Drosophila leg. We focus on this portion of the pathway because several authors suspect that it approximates an arthropod 'ground-plan' for body outgrowths (Campbell, 2002; Galindo et al, 2002; Kojima, 2004), because all of the genes illustrated are known to be involved with the patterning of appendages in beetles (Nagy and Carroll, 1994; Sanchez-Salazar et al, 1996; Beermann et al, 2001; Prpic and Tautz, 2003; Beermann and Schroder, 2004; Jockusch et al, 2004), and because six of these genes have already been shown to be expressed in developing beetle horns (aristaless (al), distal-less (dll), dachshund (dac): Moczek and Nagy, 2005; AP Moczek personal communication); wingless (wg), decapentaplegic $(d p p)$, epidermal growth factor receptor (egfr): D Emlen, Q Szafran, L Corley \& I Dworkin, in preparation).

Limb patterning is inextricably coupled with cell proliferation and appendage growth, and herein lies the exciting connection between this pathway and morphological evolution. Many of the same signal interactions that specify domains within the disc also stimulate and coordinate cell proliferation within those domains (reviews: Serrano and O'Farrell, 1997; Johnston and Gallant, 2002). This means that changes in the relative sizes of domains within a growing disc will result in changes to the relative sizes of the corresponding regions of the final structure (eg the size of the femur relative to the tibia in an insect leg), and recently several authors have been able to link variation in appendage morphology with specific changes in the domains of expression of patterning genes (eg Niwa et al, 2000; Jockusch et al, 2004; Palsson et al, 2005). In fact, it has become clear that even large-scale (eg among-species) differences in the sizes and shapes of body parts may arise from subtle, trait-specific alterations in the spatial domains and levels of expression of patterning genes (eg Abouheif and Wray, 2002; Inoue et al, 2002; Prpic et al, 2003; Beermann and Schroder, 2004; Jockusch et al, 2004). Thus, the limb-patterning pathway plays a central and crucial role in specifying the final morphology - the shape and the approximate final size - of adult insect structures, and this pathway is likely to be involved in the evolution of traits like beetle horns.

\section{Patterning and the origin of beetle horns}

All arthropod body outgrowths or appendages studied to date utilize some form of this basic patterning process during their development (eg Panganiban et al, 1997; Jockusch et al, 2004), and activation of this pathway alone is sufficient to generate novel structures - new outgrowths in new body regions (eg Campbell et al, 1993). For example, juxtaposition of Wg and Dpp signals in the anterior region of a developing Drosophila wing initiates formation of a second axis of outgrowth - a new distal tip that subsequently generates a new wing - resulting in the formation of a bifurcated, double wing blade (eg Campbell et al, 1993; Zecca et al, 1995; Serrano and O'Farrell, 1997). Similarly, reproducing this same combi- 


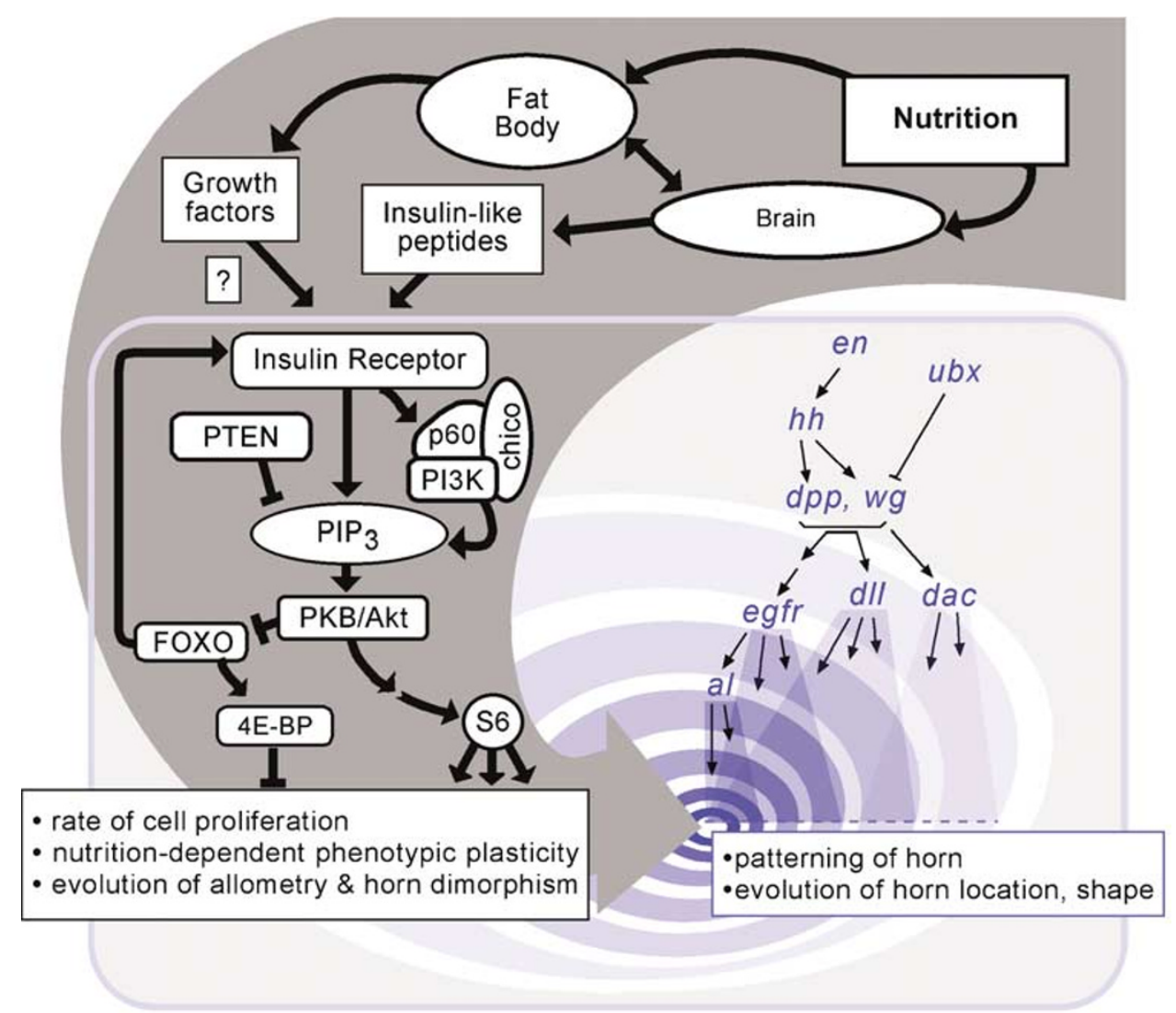

Figure 4 Two pathways putatively involved with the development and evolution of beetle horns (and other appendages/outgrowths of arthropods). The limb-patterning pathway (blue) acts largely autonomously within the cluster of epidermal cells that will form the horn (ie within the horn 'imaginal disc'). Patterning results from a hierarchical cascade of local signaling interactions that delineate precise regions within the structure, and coordinate cell proliferation within those regions (see text for references). Elements shown are all involved with the formation of an axis of outgrowth (proximal $\rightarrow$ distal), and altered expression of any of these pathway elements are predicted to change the dimensions/proportions of the resulting structure (eg the length and shape of the horn), as well as the precise location of the structure (which cells become the distal tip; dark blue ring at lower right). Cell proliferation in insect imaginal discs is modulated in response to larval nutrition. The Insulin pathway (left) incorporates long-range (whole-animal) circulating signals that, when bound to receptors within the different imaginal discs, control the rate of proliferation that occurs in the disc. Altered levels of expression of elements in this pathway changes how specific traits respond to the nutrition environment, and are predicted to change trait allometry. Reduced signaling in either of these pathways would dramatically alter horn growth, and both are candidate mechanisms for dimorphism (male dimorphism, sexual dimorphism) in horn expression. Abbreviations: limb patterning pathway, ubx, ultrabithorax; en, engrailed; hh, hedgehog; wg, wingless; dpp, decapentaplegic; dac, dachshund; dll, distal-less; egfr, epidermal growth factor receptor; al, aristaless; Insulin pathway, PTEN, protein tyrosine phosphatase; PI3K, phosphatidylinositol-3-OH-kinase; PIP $_{3}$, phosphatidylinositol $(3,4,5)$ triphosphate; PKB $(=\mathrm{Akt})$, protein kinase B; FOXO, forkhead-related transcription factor; 4E-BP, 4E-binding protein; S6, S6 kinase.

nation of signals in atypical regions of a developing leg generates a new axis of outgrowth, and a new fullyformed and segmented limb, again resulting in a bifurcated double-appendage (eg Diaz-Benjumea et al, 1994; Gibson and Schubiger, 1999). Although these novel outgrowths are generated in the laboratory, they illustrate the self-contained property of this signaling pathway, and the potential for this pathway to be involved in the evolution of novel morphological structures.

Beetle horns arose as novel morphological structures. Although their development shares many similarities with the development of other insect imaginal discs, the horns do not themselves derive from these traditional discs (at least so far as we know). Instead, they appear to have arisen as new regions of epidermal tissue that at some point in the history of the scarabs began to behave like imaginal discs. Specifically, they began to form an axis of outgrowth. This strongly suggests that the evolution of beetle horns entailed the deployment of the limb-patterning pathway in novel regions of the larval epidermis, resulting in the formation of new developmental axes of outgrowth, and new projections from the body wall. Recent experiments by Moczek and Nagy (2005) provided the first clues that this is indeed the case: they showed that the proteins of the patterning genes distal-less $(\mathrm{dll})$ and aristaless $(\mathrm{al})$ were present in beetle horn discs in regions corresponding to the distal tips of the developing horns. Similarly, we have now shown that the patterning genes wingless (wg), decapentaplegic (dpp), and epidermal growth factor receptor (egfr) also are expressed in horn discs during the period of horn growth (D Emlen, Q Szafran, L Corley and I Dworkin, in preparation). Although no studies have yet confirmed a functional role for these genes in the patterning of beetle horns, their timing and locations of expression provide compelling preliminary evidence that this patterning pathway is involved in both the development and evolution of these structures. 
Patterning and the evolution of horn location and shape In Drosophila, the limb-patterning pathway determines which cells will become the distal tip of a developing structure (ie the precise location of the point of outgrowth), and this pathway specifies the relative sizes of regions within the developing structure (ie the shape of the resulting outgrowth). Here, we use studies of the function of patterning genes in Drosophila legs to illustrate how changes in the expression of elements in this pathway might contribute to the evolution of beetle horns.

Wingless $(w g)$ and decapentaplegic $(d p p)$ are the primary organizers of imaginal discs (Serrano and O'Farrell, 1997; Johnston and Gallant, 2002; Weihe et al, 2005). Cells at their point of intersection (ie with high levels of both signals) become the distal tip of the growing appendage, and gradients of $\mathrm{Wg}$ and Dpp protein determine the amount of growth along the new proximal/distal (outgrowth) axis (Struhl and Basler, 1993; Diaz-Benjumea et al, 1994; Held et al, 1994; Serrano and O'Farrell, 1997). As a result of their role in determining the precise location of the axis of outgrowth, and their role in determining the amount of outgrowth, the patterning genes $w g$ and $d p p$ are candidates for genetic changes in horn location, and in horn size. Furthermore, because juxtaposition of these two signals can initiate new axes of outgrowth (eg bifurcation or branching of an appendage, see above), altered expression of these same two genes may underlie shifts from a single horn to a symmetrical pair of horns (eg Figure 2b), or the branching of horns (eg Dworkin et al, 2001) - in other words, they may underlie genetic changes in horn shape.

Mutations in several additional pathway elements also affect the amount of proliferation within discs and the resulting final sizes and shapes of structures, and for these same reasons are candidates for horn evolution. Four of these patterning genes are expressed specifically at the distal tips of outgrowths/appendages (distal-less (dll), arista-less (al), epidermal growth factor receptor (egfr)), or in the medial regions of appendages (dachshund (dac)), and are required for growth of their respective regions within an appendage (eg Diaz-Benjumea et al, 1994; Serrano and O'Farrell, 1997; Galindo et al, 2002; Kojima, 2004; Weihe et al, 2005). If they function similarly in scarabs, then changes in levels or domains of expression of any of these genes could alter the shape, the final size, or even the presence/absence of a beetle horn.

In summary, the limb-patterning pathway is responsible for determining the shapes, and the approximate final sizes of adult morphological structures in insects. The specification of pattern results from a largely selfcontained (autonomous) and local (within-disc) cascade of genetic interactions whereby each tier of expressed genes initiates the next, and where particular combinations and levels of expressed genes interact to specify both the regional identity, and the relative amounts of growth, of the affected cells. This patterning process is self-contained in the sense that it can unfold largely in the absence of external signals, and because it can be initiated in novel developmental contexts/locations.

However, growth of insect imaginal discs is not entirely autonomous, and under natural conditions the amount of growth is modulated by several long-range signals that circulate globally within the insect, and that couple cell proliferation with external circumstances such as nutrition (Hipfner and Cohen, 1999; Stern and Emlen, 1999; Bryant, 2001; Goberdhan and Wilson, 2002; Emlen and Allen, 2004; Weihe et al, 2005). One of these signals is insulin.

\section{The insulin pathway and the evolution of allometry}

Cell proliferation requires high levels of protein synthesis, and in both vertebrates and insects, this process is regulated by the insulin pathway (Johnston and Gallant, 2002). In insects, insulin-like peptides (secreted primarily by insulin-producing cells in the brain), probably in cooperation with growth factors (secreted by the fat bodies), bind to the insulin receptor and activate an evolutionarily conserved signal transduction cascade that controls the activity of the protein translation machinery (Weinkove and Leevers, 2000; Claeys et al, 2002; Figure 4)

The insulin pathway is an ideal candidate for the developmental mechanism of trait allometry because levels of both insulin and growth factor signals are sensitive to larval nutrition, and because these signal levels affect overall rates of cell proliferation in imaginal discs during the period of disc growth (Kawamura et al, 1999; Day and Lawrence, 2000; Masumura et al, 2000; Britton et al, 2002; Ikeya et al, 2002; Nijhout and Grunert, 2002). Importantly, although the signals of this pathway circulate throughout the insect, both the receptor and pathway are activated within target tissues; in this case, within imaginal discs. Thus, a dialogue between circulating signals and tissue-level sensitivities to those signals determines the patterns of growth of each structure, and genetic differences among discs in how they respond to the insulin signaling 'environment' comprises a plausible mechanism for the evolution of trait allometries (Nijhout, 2003a; Emlen and Allen, 2004; Shingleton et al, 2005).

If the insulin pathway is involved with the nutritiondependent modulation of trait growth, then we can make several explicit predictions. Differences among traits (eg imaginal discs) in how they respond to insulin signals should affect both their overall rates of proliferation, and, just as importantly, it should affect the sensitivity of their proliferation to the nutrition environment: discs that are highly sensitive to insulin signals are expected to exhibit nutrition-dependent (plastic) variation in growth and final trait sizes, whereas discs less sensitive to insulin signals are expected to exhibit nutrition-independent (canalized) patterns of growth and final trait size. Stated another way, traits sensitive to insulin signals should display steep and positive allometries in natural populations (trait size tightly correlated with among-individual variation in body size), and traits insensitive to insulin signals should have shallow/flat allometry slopes (trait size not correlated with variation in body size).

Each of these predictions has been borne out in Drosophila. Genetic perturbations to the insulin pathway within specific discs dramatically alters the rate of proliferation and the final sizes of those traits (Weinkove et al, 1999; Goberdhan and Wilson, 2002; Puig et al, 2003; Mirth et al, 2005; Shingleton et al, 2005), and highly nutrition-sensitive (plastic) traits with steep allometry slopes (eg wings) are much more sensitive to insulin signaling (and to perturbations in insulin signaling) than 
are nutrition-insensitive (canalized) traits with shallow allometry slopes (eg genitalia; Shingleton et al, 2005). For these reasons, the insulin pathway is now thought to be the primary physiological mechanism underlying nutrition-dependent modulation of imaginal disc growth generally (Bryant, 2001; Britton et al, 2002; Johnston and Gallant, 2002; Weihe et al, 2005), and trait allometry specifically (Goberdhan and Wilson, 2002; Nijhout, 2003b; Emlen and Allen, 2004; Mirth et al, 2005; Shingleton et al, 2005).

\section{The fourth trajectory: evolution of horn dimorphism}

The insulin pathway is also a likely candidate for the mechanisms of dimorphism in horn expression. Both sexual dimorphism and male dimorphism involve a reprogramming of trait allometry (Figure $2 \mathrm{~d}$ ). In the beetle $O$. nigriventris, horn growth in large males is sensitive to nutrition, and across their size range horns scale steeply and positively with body size. Horn growth in small males and females is less sensitive to nutrition, and these horns do not scale with body size (flat allometry).

We predicted that if the insulin pathway was involved with this switch in horn allometry, then horn discs in large males would be sensitive to circulating insulin signals, but horn discs in small males and females would not. Specifically, we predicted that a truncation event somewhere in the insulin pathway in the horn discs of small males and females would uncouple proliferation in these structures from circulating insulin signals shutting off cell proliferation irrespective of the actual nutritional state or body size of the animal. As a first test of these hypotheses, we quantified relative expression of the insulin receptor gene (InR) in the horn discs of large males, small males, and females of this species. We cloned by degenerate PCR a $452 \mathrm{bp}$ fragment of an $O$. nigriventris InR homolog and performed quantitative real-time PCR. We found that by the end of the period of horn growth (Period II), InR transcript abundances differed significantly between individuals with (large males) and without (small males, females) horn growth, and in a direction consistent with a disruption of pathway activity in the horn discs of 'reprogrammed' individuals (Figure 5). Although this represents only one element in the insulin pathway (and only one of five species we are currently studying), these results already implicate altered insulin signaling in the mechanism suppressing horn growth in small males and females.

We now suspect that in $O$. nigriventris the insulin pathway is truncated at some point downstream from the insulin receptor, and that this comprises the reprogramming event resulting in horn dimorphism (ie altered insulin signaling appears to be one of the 'downstream' pathways regulated by the endocrine threshold mechanism determining horn fate during Period I). In this case, reduced signaling through this pathway would keep the fork-head transcription factor gene FOXO in an activated state, which both shuts off cell proliferation, and upregulates transcription of the insulin receptor in these horn discs (Figure 5).

Interestingly, this situation is what occurs systemically in animals that are starved: it is a physiological mechanism that arrests overall growth under starvation conditions (Junger et al, 2003; Kramer et al, 2003; Puig and

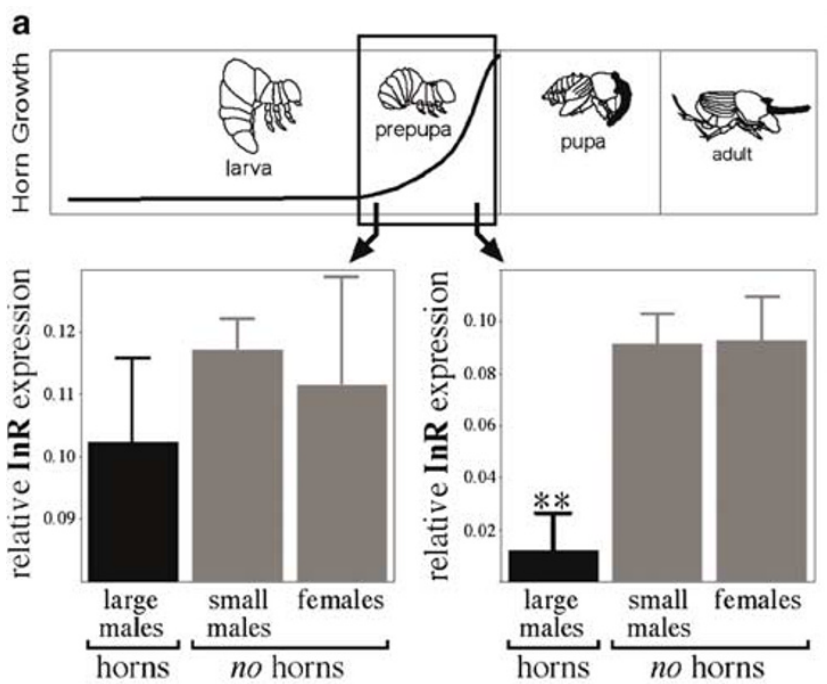

b

Large Males
(horn growth)

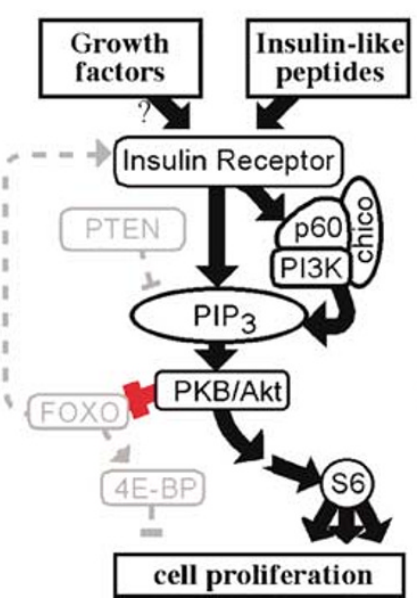

C Small Males, Females

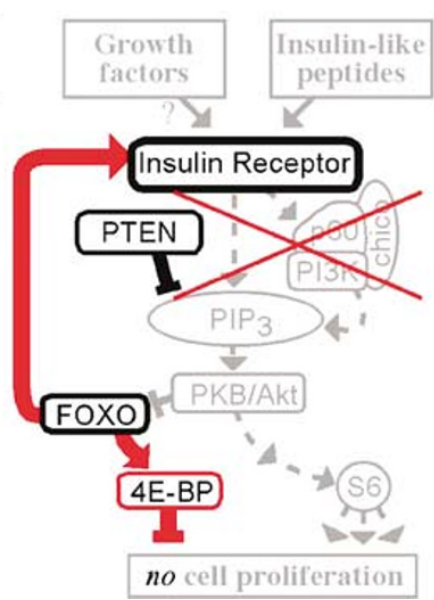

Figure 5 Example of candidate gene transcript abundance associated with horn expression. (a) Quantitative real-time PCR was conducted on the O. nigriventris InR transcript, using $28 \mathrm{~S}$ as a control for overall levels of RNA (Pfaffl, 2004; Johnson et al, 2005). At the beginning of horn growth (early Period II) there is no evidence for differential expression of the InR gene between large males which grow horns, and small males and females who lack horns. However, during the period of maximal horn growth (late Period II) there is a highly significant $(P<0.0001)$ difference in expression of the InR gene that is associated with horn growth: horn cells from small males and females had significantly higher levels of InR transcript than similar cells from large males. (b) The insulin signaling pathway, illustrating one explanation for this result: as signaling through the insulin pathway is increased overall in large males, the expression of InR decreases in horn discs due to kinase-dependent inactivation of its transcriptional activator FOXO by PKB/Akt (red bar; Kramer et al, 2003; Puig and Tijan, 2005). (c) In horn discs of small males and females pathway activity is truncated at some point downstream from the insulin receptor (tissue 'reprogramming' resulting from the mechanism of horn dimorphism). Reduced signaling through this pathway keeps FOXO in an activated state, causing an upregulation of InR transcription (Puig and Tijan, 2005) and shutting off cell proliferation through the transcriptional inhibitor 4E-BP (red arrows; Junger et al, 2003). Data from D Emlen, L Corley, I Dworkin and Q Szafran, in preparation. 
Tijan, 2005). However, large females, and probably even small males are not starved, and in these animals the arrested development applies to only a single structure, the horns, at a time when other traits like wings and eyes are still growing. Thus, it appears that both male dimorphism and sexual dimorphism may have evolved in part through the co-option of an existing physiological mechanism for coping with poor nutrition. Coupling the activity of this pathway in developing horn discs with either the attainment of a threshold body size (male dimorphism), or with a genetic factor associated with sex (sexual dimorphism), could have reprogrammed patterns of horn growth in specific subsets of the population (eg small males, females), and led to the evolution of dimorphism in horn expression.

The limb-patterning pathway also may be involved in the reprogramming of horn growth in dimorphic beetle taxa. Moczek and Nagy (2005) found clear differences in the domains of expression of distal-less (dll) and aristaless (al) proteins when they compared the horn discs of large males, small males, and females of $O$. nigriventris and $O$. taurus (see also Moczek, this issue). We detected significant differences in the relative transcript abundances of wingless $(w g)$ and decapentaplegic (dpp) in horn discs of these same categories of individuals in $O$. nigriventris (D Emlen, Q Szafran, L Corley, I Dworkin, in preparation), and are currently measuring them in the dynastine beetle Xylotrupes gideon. Both studies detected differences in the relative expression of patterning genes consistent with a role for this pathway in the mechanisms of horn dimorphism. Although it will still be necessary to confirm functional roles for these genes in the regulation of horn growth, it is already becoming clear that both the limb-patterning and the insulin pathways affect the amount of cell proliferation that occurs in developing beetle horns, and we suspect that both pathways are also involved with the suppression (or regression - see Moczek this issue) of horn growth in dimorphic taxa.

\section{The next steps: current research and future directions}

This paper illustrates what we consider to be the essential first step in any candidate gene study: identifying the most relevant candidate pathways and genes. Our next steps involve testing for functional roles of these pathways in each of the four trajectories of horn evolution. We are cloning fragments of four patterning and five insulin pathway genes from several different scarab species, chosen from a phylogeny to encompass both head and thoracic horns, species with and without horn dimorphism, and three of the four principle clades of scarabs with exaggerated weapons (Scarabaeinae, Dynastinae, Lucanidae; Figure 6). We are using quantitative measures of the expression of these genes (eg rtPCR) to assess the activities of each developmental pathway. To study allometry, we are comparing insulin pathway activity in wings, horns and genitalia - traits that differ in their allometry - and we are comparing conspecific populations with divergent allometries. To study dimorphism, we are comparing pathway activities in horns, which are reprogrammed (dimorphism), to wings, which are not, to begin to discern more precisely where in each pathway activity is truncated (the locus of reprogramming). To study location and shape, we are capitalizing on the tremendous variation present within each species, and we are measuring the relative activity of the patterning pathway in individuals with horns that differ in their curvature, branching, and location (eg center $v s$ sides of the head). In all cases, we are complementing descriptive measures of pathway activity (quantitation of relative candidate gene expression) with perturbation experiments that alter either insulin signaling (eg added insulin, RNAi 'knockdown' of the insulin receptor), or limb patterning (RNAi knockdown of $w g, e g f r)$, to confirm functional roles for each pathway in the regulation of horn growth, and in the evolution of horn location, shape, allometry and dimorphism.

Lessons learned so far from these studies of development mirror what we see when we map horns onto phylogenies: these complex morphological structures are astonishingly evolutionarily labile. It does not appear to be difficult to generate the types of morphological changes that we observe, and we now suspect that subtle genetic changes in just a handful of elements in these two pathways would be sufficient to generate all four of the major trajectories of horn evolution. Overall, our goal is to use this comparative study to reconstruct historical patterns of evolution of the developmental mechanisms regulating horn growth - an exciting step in a much larger study of the origin and evolutionary radiation of these weapons of sexual selection. We end by illustrating just one of the ways that information about development may help resolve long-standing questions of character evolution.

\section{Mystery of the scarabs resolved?}

Biologists have long recognized that the scarabs seemed to have an intrinsic predisposition for the evolution of exaggerated horns (eg Darwin, 1871; Lameere, 1904; Arrow, 1951), yet no scarab systematist that we are aware of has reconstructed the ancestor of the scarabs as a beetle with horns; there simply are too many hornless species, and the major clades with horns are too widely dispersed within this multitude of hornless taxa (Figure 6). This clear pattern led Arrow to conclude in his treatise 'The Horned Beetles' (1951) that 'it is certain that these horns have had no common origin' (p. 94). Recently, our studies of horn development have caused us to revisit this longstanding 'mystery of the scarabs,' and this developmental perspective has led us to a very different conclusion.

Most scarab horns are dimorphic (review: Emlen and Nijhout, 2000). Dimorphic mechanisms enable the complete suppression of horn growth in subsets of individuals (eg small males, females), and breakdowns in these mechanisms can lead to sudden reappearances of horns either in the lab (eg experiments perturbing hormone levels during the period of horn growth; Emlen and Nijhout, 1999; Moczek and Nijhout, 2002) or in nature (eg 'gynandromorph' females with full expression of 'male' horns; Lachaume, 1983; Dechambre, 1987; Ratcliffe, 1989).

As these developmental 'switch' or threshold mechanisms can lead to sudden reversals in the expression (or suppression) of complex morphological traits, they are predicted to facilitate rapid and repeated evolution of 


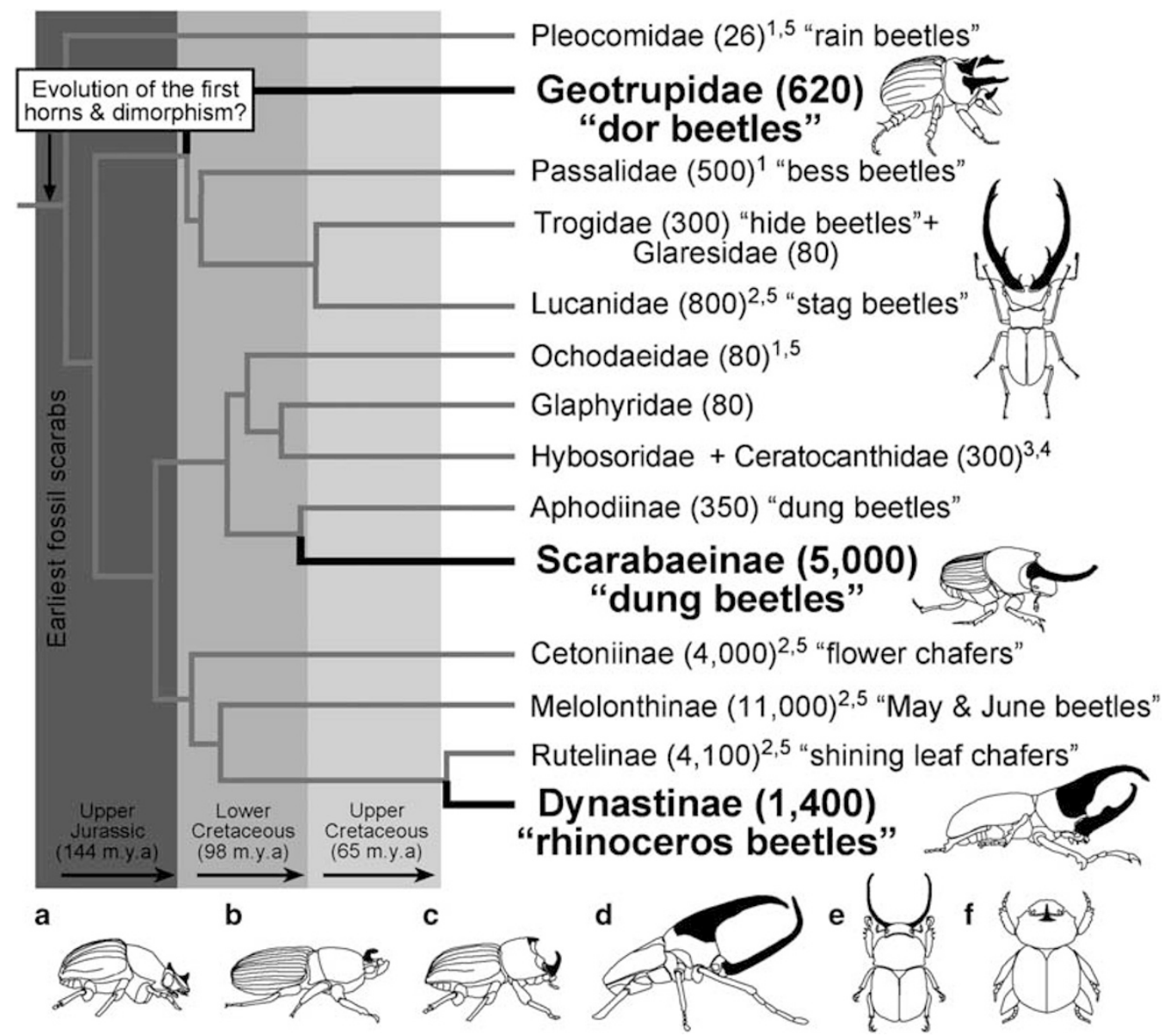

Figure 6 Partial phylogeny for the families and subfamilies of scarab beetles (Coleoptera: Scarabaeoidea) illustrating lineages with head or pronotal (thorax) horns (approximate no. species in parentheses). The majority of species with exaggerated horns are concentrated within three distantly related clades (Geotrupidae, Scarabaeinae, Dynastinae) that collectively represent only $20 \%$ of extant scarab species. For this reason, horns are thought to have arisen multiple times independently within the superfamily, leading Darwin and others to speculate on the 'special tendency' of scarabs towards evolution of enlarged horns. However, all but three of the included clades contain either rudimentary horns (1), at least a few genera or species with enlarged horns (2) or pupal horns (3), and one completely hornless subfamily contains mutant individuals with horns (4). Even the lucanids, which primarily produce enlarged mandibles as weapons, contain species with head and pronotal horns (eg Sinodendron). At least nine clades also contain threshold mechanisms for dimorphic horn expression (5). We interpret these as evidence for an inherited developmental capacity for the production of horns, and suggest that the ancestor of the scarabs may have had both horns and horn dimorphism. Representative horned species from primarily 'hornless' clades: (a) Pleocoma marquai (Pleocomidae); (b) Odontotaenius disjunctus (Passalidae) (c) Sinodendron cylindricum (Lucanidae); (d) Theodosia viridaurata (Cetoniinae); (e) Fruhstorferia sexmaculata (Rutelinae); (f) mutant 'horned' individual of Pterorthochaetes armatus (Ceratocanthidae). Tree topology partially from Smith et al (in review); Browne and Scholtz, 1998; Browne and Scholtz, 1999. Node ages based on fossil records (Krell 2000). Species numbers and taxon descriptions from Ratcliffe and Jameson (eds) Generic guide to new world scarabs (http://www-museum.unl.edu/research/entomology/ Guide/index4.htm).

these structures (West-Eberhard, 2003). Within the beetle genus Onthophagus, threshold mechanisms of dimorphism appear to have contributed to a mosaic pattern of horn evolution (multiple gains and losses of horns; Emlen et al, 2005a), and we have begun to suspect that these same mechanisms might explain patterns of horn evolution within the scarabs as a whole. All of the principle clades of horned scarabs (Figure 6) contain species with pronounced male and sexual dimorphism, suggesting that the origin of these regulatory processes may predate the divergence of these lineages - that is both horns and horn dimorphism may have been present in the common ancestor to all of the scarabs. If true, this would mean that the developmental capacity to suppress horn growth may be a shared feature of all scarabs; it would also mean that the tens of thousands of extant hornless scarab species were secondarily hornless.
Several observations - all reflecting a developmental perspective - suggest that this may in fact be the case. First, most of the 'hornless' families and subfamilies of scarabs contain at least a few species with either rudimentary horns (eg Plecomidae, Passalidae, Ochodaidae, Orphninae), or with fully-developed horns (eg Melolonthinae, Cetoniinae, Rutelinae). The locations, shapes and patterns of expression (dimorphism) of these horns are often similar to the horns of other scarabs (Figure 6). Second, the pupal stages of many scarabs have thoracic 'horns', and these are often present in individuals (eg females) or species that lack this horn as adults. Pupal 'horns' may serve a current function as support structures protecting animals during the vulnerable metamorphic molt (Main, 1922; Halffter and Matthews, 1966; Edmonds and Hallfter, 1978), but they may also represent developmental carry-overs from a 
horn that was present in the adult stages of an ancestor (Ballerio, 1999; A Moczek and T Cruickshank, personal communication). Third, even within completely hornless species - in one case a species within a completely hornless subfamily, the Ceratocanthidae, which have been a distinct clade for at least 65 million years - mutant adult individuals occasionally appear with fully developed horns, and these horns also resemble the horns of other scarabs (Figure 6f; Ziani, 1995; Ballerio, 1999; A. Ballerio, personal communication). We interpret all of these as evidence for the existence of a mechanism for horn development in these scarab families - a mechanism that is apparently suppressed in most individuals of most of species. Consideration of this developmental potential for horn growth leads to a very different reconstruction for the ancestral state of the earliest scarabs, and we now suspect that these Jurassic beetles may have had both horns, and horn dimorphism.

What was the 'special tendency' of the scarabs that predisposed so many lineages towards the evolution of horns? We suggest that it was a shared and inherited developmental capacity both for the production of horns, and for the facultative suppression of horn growth. The first scarabs are thought to have excavated burrows either into the stems of cycads (Lameere, 1904) or into the soil (Scholtz and Chown, 1995). Contests over restricted (defendable) substrates are an almost universal feature of extant horned beetle species (eg Eberhard, 1978; Eberhard, 1987; Rasmussen, 1994; Emlen, 2000; Iguchi, 2001; Hongo, 2003), and the first scarab horns may have aided animals in battles within the confines of these early burrows. We further suggest that the mechanisms of dimorphism facilitated rapid gains, losses, and regains of horns in the history of these beetles, and contributed to the patterns observed by Darwin, Lameere, Arrow and others: multiple, disparate lineages of scarabs that appear to have independently evolved horns.

There are several ways to begin to test this hypothesis. For example, we predict that mutant individuals with horns (teratologies) will be found in additional lineages of hornless scarabs, and that fossils of early scarabs will be found with horns. But the most compelling tests are likely to come from studies of horn development. Comparative studies of development have helped resolve several long-standing controversies involving the deep past (eg the origin of insect wings (Shubin et al, 1997) and wing polyphenism (Abouheif and Wray, 2002)), in part because they bring an entirely new and informative suite of characters to these analyses. In this case, we will compare the endocrine mechanisms generating dimorphism, and the 'downstream' pathways involved with horn growth (limb patterning, insulin), in three widely divergent clades of scarabs representing what are traditionally considered to be three independent evolutionary origins of horns (scarabaeinae, dynastinae, lucanidae), to search for signatures of a shared past embedded within the details of their respective developmental mechanisms.

\section{Acknowledgements}

We thank Olga Helmy for help with the illustrations, Mary Liz Jameson, Brett Ratcliffe and Andrew Smith for help with scarab phylogenies, J Mark Rowland for sharing unpublished data, Paul Brakefield, Kerry Bright, Vernon French, Lewis I Held, Jr, and two anonymous reviewers for helpful comments on the manuscript, A Ballerio for sharing ideas and photographs of mutant ceratocanthids, and the National Science Foundation for funding this research (IBN-0092873 to DJE).

\section{References}

Abouheif E, Wray GA (2002). Evolution of the gene network underlying wing polyphenism in ants. Science 297: 249-252.

Arrow GJ (1951). Horned Beetles. Dr W. Junk Publishers: The Hague.

Ballerio A (1999). Revision of the genus Pterorthochaetes, first contribution (Coleoptera: Scarabaeoidea: Ceratocanthidae). Folia Heyrovskiana 7: 221-228.

Bates HW (1863). The Naturalist on the River Amazons. Reprint. 1989. Penguin Books: London.

Beebe W (1944). The function of secondary sexual characters intwo species of Dynastinae (Coleoptera). Zoologica 29: 53-58.

Beermann A, Jay DG, Beeman RW, Hulskamp M, Tautz D, Jurgens G (2001). The Short antennae gene of Tribolium is required for limb development and encodes the orthologue of the Drosophila Distal-less protein. Development 128: 287-297.

Beermann A, Schroder R (2004). Functional stability of the aristaless gene in appendage tip formation during evolution. Dev Genes Evol 214: 303-308 [E-pub 2004 May 18].

Brakefield PM, French V, Zwaan BJ (2003). Development and the genetics of evolutionary change within insect species. Ann Rev Ecol Evolut Systemat 34: 633-660.

Britton JS, Lockwood WK, Li L, Cohen SM, Edgar BA (2002). Drosophila's insulin/PI3-kinase pathway coordinates cellular metabolism with nutritional conditions. Dev Cell 2: 239-249.

Browne J, Scholtz C (1998). Evolutioon of the scarab hindwing articulation and wing base: a contribution toward the phylogeny of the Scarabaeidae (Scarabaeoidea: Coleoptera). Syst Entomol 23: 307-326.

Browne J, Scholtz CH (1999). A phylogeny of the families of Scarabaeoidea (Coleoptera). Syst Entomol 24: 51-84.

Bryant PJ (2001). Growth factors controlling imaginal disc growth in Drosophila. Novartis Found Symp 237: 182-194 Discussion 194-202.

Burmeister H (1847). Handbuch der Entomologie 5. Dynastinae: Berlin.

Campbell G (2002). Distalization of the Drosophila leg by graded EGF-receptor activity. Nature 418: 781-785.

Campbell G, Weaver T, Tomlinson A (1993). Axis specification in the developing Drosophila appendage: the role of wingless, decapentaplegic, and the homeobox gene aristaless. Cell 74: 1113-1123.

Carroll SB, Grenier JK, Weatherbee SD (2001). From DNA to Diversity: Molecular Genetics and the Evolution of Animal Design. Blackwell Pub.: Malden, MA.

Claeys I, Simonet G, Poels J, Van Loy T, Vercammen L, De Loof A, vanden Broeck J (2002). Insulin-related peptides and their conserved signal transduction pathway. Peptides 23: 807-816.

Darwin C (1871). The Descent of Man and Selection in Relation to Sex. Random House, Modern Library: New York.

Day SJ, Lawrence PA (2000). Measuring dimensions: The regulation of size and shape. Development 127: 2977-2987.

Dechambre R-P (1987). Un cas de gynandromorphisme biparti ches Megasoma elephas (F.) Coleoptera: Dynastidae). Ann Soc Ent france (NS) 23: 209-211.

Diaz-Benjumea FJ, Cohen B, Cohen SM (1994). Cell interaction between compartments establishes the proximal-distal axis of Drosophila legs. Nature 372: 175-179.

Drury D (1770). Illustrations of Natural History. B. White Publisher: London. Vol. 3, 150p. 
Dworkin IM, Tanda S, Larsen E (2001). Are entrenched characters developmentally constrained? Creating biramous limbs in an insect. Evol Dev 3: 424-431.

Eberhard WG (1978). Fighting behavior of male Golofa porteri beetles (Scarabaeidae: Dynastinae). Psyche 83: 292-298.

Eberhard WG (1987). Use of horns in fights by the dimorphic males of ageopsis-nigricollis coleoptera scarabeidae dynastinae. J Kansas Entomol Soc 60: 504-509.

Edmonds WD, Hallfter G (1978). Taxonomic review of immature dung beetles of the subfamily Scarabaeinae (Coleoptera: Scarabaeidae). Syst Entomol 3: 307-331.

Emlen DJ (1994). Environmental control of horn length dimorphism in the beetle Onthophagus acuminatus (Coleoptera: Scarabaeidae). Proc R Soc London 256: 131-136.

Emlen DJ (2000). Integrating development with evolution: a case study with beetle horns. Bioscience 50: 403-418.

Emlen DJ, Allen CE (2004). Genotype to phenotype: physiological control of trait size and scaling in insects. Integrative Comparative Biol 43: 617-634.

Emlen DJ, Hunt J, Simmons LW (2005a). Evolution of sexual dimorphism and male dimorphism in the expression of beetle horns: phylogenetic evidence for modularity, evolutionary lability, and constraint. Am Naturalist 166: S42-S68.

Emlen DJ, Marangelo J, Ball B, Cunningham CW (2005b). Diversity in the weapons of sexual selection: horn evolution in the beetle genus Onthophagus (Coleoptera: Scarabaeidae). Evolution 59: 1060-1084.

Emlen DJ, Nijhout HF (1999). Hormonal control of male horn length dimorphism in the dung beetle Onthophagus taurus (Coleoptera: Scarabaeidae). J Insect Physiol 45: 45-53.

Emlen DJ, Nijhout HF (2000). The development and evolution of exaggerated morphologies in insects. Annu Rev Entomol 45: 661-708.

Emlen DJ, Nijhout HF (2001). Hormonal control of male horn length dimorphism in Onthophagus taurus (Coleoptera: Scarabaeidae): a second critical period of sensitivity to juvenile hormone. J Insect Physiol 47: 1045-1054.

Enrodi S (1985). The Dynastinae of the World. W. Junk: Boston, MA.

Fischer GvW (1823). Coleoptera quaedam exotica descripta. Mem Soc Nat Mosc 6: 2.

Fitzpatrick MJ, Ben-Shahar Y, Smid HM, Vet LEM, Robinson GE, Sokolowski MB (2005). Candidate genes for behavioural ecology. Trends Ecol Evol 20: 96-104.

Galindo MI, Bishop SA, Greig S, Couso JP (2002). Leg patterning driven by proximal-distal interactions and EGFR signaling. Science 297: 256-259.

Gerhart J, Kirschner M (1997). Cells, Embryos, and Evolution: Toward a Cellular and Developmental Understanding of Phenotypic Variation and Evolutionary Adaptability. Blackwell Science: Malden, Mass.

Gibson MC, Schubiger G (1999). Hedgehog is required for activation of engrailed during regeneration of fragmented Drosophila imaginal discs. Development 126: 1591-1599.

Goberdhan DC, Wilson C (2002). Insulin receptor-mediated organ overgrowth in Drosophila is not restricted by body size. Dev Genes Evol 212: 196-202.

Grimaldi D, Engel M (2005). Evolution of the Insects. Cambridge University Press: Cambridge, MA

Hadorn E (1966). Konstanz, Wechsel und Typus der determination und differenzierung in Zellen aus mannlichen Genitalanlagen von Drosophila melanogaster nach Dauerkultur in vivo. Devl Biol 13: 424-509.

Halffter G, Matthews EG (1966). The natural history of the dung beetles of the subfamily Scarabaeinae (Coleoptera: Scarabaeidae). Folia Entologica Mexicana 12-14: 1-313.

Hall BK (1992). Evolutionary Developmental Biology. Chapman \& Hall: New York.

Held Jr LI (2002). Imaginal Discs: The Genetic and Cellular Logic of Pattern Formation. Cambridge University Press: New York.
Held Jr LI, Heup MA, Sappington JM, Peters SD (1994). Interactions of decapentaplegic, wingless, and Distal-less in the Drosophila leg. Roux's Arch Dev Biol 203: 310-319.

Hipfner DR, Cohen SM (1999). New growth factors for imaginal discs. Bioessays 21: 718-720.

Hongo Y (2003). Appraising behaviour during male-male interaction in the Japanese horned beetle Trypoxylus dichotomus septentrionalis (Kono). Behaviour 140: 501-517.

Hunt J, Simmons L (2001). Status-dependent selection in the dimorphic beetle Onthophagus taurus. Proc $R$ Soc Ser B 268: 2409-2414.

Hunt J, Simmons LW (2000). Maternal and paternal effects on offspring phenotype in the dung beetle Onthophagus taurus. Evolution 54: 936-941.

Iguchi Y (1998). Horn dimorphism of Allomyrina dichotoma septentrionalis (Coleoptera: Scarabaeidae) affected by larval nutrition. Ann Entomol Soc Am 91: 845-847.

Iguchi Y (2001). Differences in the frequency of fights between minor and major males in the horned beetle Trypoxylus dichtomus septentrionalis (Coleoptera: Scarabaeidae). Entomol Rev Japan 56: 11-14.

Ikeya T, Galic M, Belawat P, Nairz K, Hafen E (2002). Nutrientdependent expression of insulin-like peptides from neuroendocrine cells in the CNS contributes to growth regulation in Drosophila. Curr Biol 12: 1293-1300.

Inoue Y, Mito T, Miyawaki K, Matsushima K, Shinmyo Y, Heanue TA et al (2002). Correlation of expression patterns of homothorax, dachshund, and Distal-less with the proximodistal segmentation of the cricket leg bud. Mech Dev 113: 141-148.

Jockusch EL, Williams TA, Nagy LM (2004). The evolution of patterning of serially homologous appendages in insects. Dev Genes Evol 214: 324-338.

Johnson DR, Lee PKH, Holmes VF, Alvarez-Cohen L (2005). An internal reference technique for accurately quantifying specific mRNAs by real-time PCR with application to the tceA reductive dehalogenase gene. App Env Microbiol 2005: 3866-3871.

Johnston LA, Gallant P (2002). Control of growth and organ size in Drosophila. Bioessays 24: 54-64.

Junger MA, Rintelen F, Stocker H, Wasserman JD, Vegh M, Radimerski T et al (2003). The Drosophila forkhead transcription factor FOXO mediates the reduction in cell number associated with reduced insulin signaling. J Biol 2: 20.

Karino K, Seki N, Chiba M (2004). Larval nutritional environment determines adult size in Japanese horned beetles Allomyrina Dichotoma. Ecol Res 19: 663-668.

Kawamura K, Shibata T, Saget O, Peel D, Bryant PJ (1999). A new family of growth factors produced by the fat body and active on Drosophila imaginal disc cells. Development 126: 211-219.

Kojima T (2004). The mechanism of Drosophila leg development along the proximodistal axis. Develop Growth Differ 46: 115-129.

Kopec S (1922). Studies on the necessity of the brain for the inception of insect metamorphosis. Biol Bull 42: 323-341.

Kramer JM, Davidge JT, Lockyer JM, Staveley BE (2003). Expression of Drosophila FOXO regulates growth and can phenocopy starvation. BMC Dev Biol 3: 5.

Lachaume G (1983). Goliathini Première Partie. Les Coléopteres du Monde: Compiègne.

Lameere A (1904). L'Evolution des ornaments sexuels. Bull Ac Belgique 1904: 1327-1364.

Main H (1922). Notes on the metamorphoses of Onthophagus taurus. Proceedings of the Entomological Society of London. xiv-xvi, plate A.

Masumura M, Satake SI, Saegusa H, Mizoguchi A (2000). Glucose stimulates the release of bombyxin, an insulinrelated peptide of the silkworm Bombyx mori. Gen Compar Endocrinol 118: 393-399. 
Mirth C, Truman JW, Riddiford LM (2005). The Role of the Prothoracic Gland in Determining Critical Weight for Metamorphosis in Drosophila melanogaster. Curr Biol 15 Published online October 25, 2005. 10.1016/j.cub.2005.09.017.

Moczek AP, Emlen DJ (1999). Proximate determination of male horn dimorphism in the beetle Onthophagus taurus (Coleoptera: Scarabaeidae). J Evolut Biol 12: 27-37.

Moczek AP, Nagy LM (2005). Diverse developmental mechanisms contribute to different levels of diversity in horned beetles. Evol Dev 7: 175-185.

Moczek AP, Nijhout HF (2002). Developmental mechanisms of threshold evolution in a polyphenic beetle. Evol Devol 4: 252-264.

Nagy LM, Carroll S (1994). Conservation of wingless patterning functions in the short-germ embryos of Tribolium castaneum. Nature 367: 460-463.

Nijhout HF (2003a). The control of body size in insects. Devl Biol 261: $1-9$.

Nijhout HF (2003b). The control of growth. Development 130: $1-5$.

Nijhout HF, Grunert LW (2002). Bombyxin is a growth factor for wing imaginal disks in Lepidoptera. Proc Natl Acad Sci USA 99: 15446-15450.

Niwa N, Inoue Y, Nozawa A, Saito M, Misumi Y, Ohuchi H et al (2000). Correlation of diversity of leg morphology in Gryllus bimaculatus (cricket) with divergence in dpp expression pattern during leg development. Development 127: 4373-4381.

O'Brochta DA, Bryant PJ (1987). Distribution of s-phase cells during the regeneration of Drosophila imaginal wing discs. Devell Biology 119: 137-142.

Palsson A, Dodgson J, Dworkin I, Gibson G (2005). Tests for the replication of an association between Egfr and natural variation in Drosophila melanogaster wing morphology. BMC Genet 6: 44.

Panganiban G, Irvine SM, Lowe C, Roehl H, Corley LS, Sherbon $B$ et al (1997). The origin and evolution of animal appendages. Proc Natl Acad Sci USA 94: 5162-5166.

Paulian R (1935). Le polymorphisme des males de Coléopteres. In: Tessier G (ed) Exposés de Biométrie et Statistique Biologique IV. Actualités Scientifiques et Industrielles. Hermann: Paris. pp 1-33.

Pfaffl MW (2004). Quantification strategies in real-time PCR. In: Bustin SA (ed) A-Z of Quantitative PCR. International University Line Publishers: Portland OR. 912pp.

Pohley H-J (1965). Regeneration and the moulting cycle in Ephestia kühniella. In: Kiortsis V, Trampusch HAL (eds) Regeneration in Animals and Related Problems. North-Holland Publishing Company: Amsterdam. pp 324-330.

Prpic NM, Janssen R, Wigand B, Klingler M, Damen WG (2003). Gene expression in spider appendages reveals reversal of exd/hth spatial specificity, altered leg gap gene dynamics, and suggests divergent distal morphogen signaling. Dev Biol 264: 119-140.

Prpic NM, Tautz D (2003). The expression of the proximodistal axis patterning genes Distal-less and dachshund in the appendages of Glomeris marginata (Myriapoda: Diplopoda) suggests a special role of these genes in patterning the head appendages. Dev Biol 260: 97-112.

Puig O, Marr MT, Ruhf ML, Tjian R (2003). Control of cell number by Drosophila FOXO: downstream and feedback regulation of the insulin receptor pathway. Genes Dev 17: 2006-2020.
Puig O, Tijan R (2005). Transcriptional feedback control of insulin receptor by dFOXO/FOXO1. Genes Dev 19: 2435-2446.

Raff RA (1996). The Shape of Life: Genes, Development, and the Evolution of Animal Form. University of Chicago Press: Chicago.

Raff RA (2000). Evo-devo: The evolution of a new discipline. Nat Rev Genet 1: 74-79.

Rasmussen JL (1994). The influence of horn and body size on the reproductive behavior of the horned rainbow scarab beetle Phanaeus difformis (Coleoptera: Scarabaeidae). J Insect Behav 7: 67-82.

Ratcliffe BC (1989). A case of gynandromorphy in Golofa tersander Burmeister (Coleoptera: Scarabaeidae). Coleopterists Bull 43: 256-257.

Sanchez-Salazar J, Pletcher MT, Bennett RL, Brown SJ, Dandamudi TJ, Denell RE et al (1996). The Tribolium decapentaplegic gene is similar in sequence, structure, and expression to the Drosophila dpp gene. Dev Genes Evolut 206: 237-246.

Scholtz CH, Chown SL (1995). The evolution of habitat use and diet in the Scarabaeoidea: a phylogenetic approach. In: Pakaluk AFJ, Slipinski SA (eds) Biology, Phylogeny, and Classification of the Coleoptera Muzeum $i$ Instytut Zoologii PAN. Warszawa: Poland. pp 335-374.

Serrano N, O'Farrell PH (1997). Limb morphogenesis: connections between patterning and growth. Curr Biol 7: R186-R195.

Shingleton AW, Das J, Vinicius L, Stern DL (2005). The temporal requirements for insulin signaling during development in Drosophila. PLoS Biol 3: 1607.

Shubin N, Tabin C, Carroll S (1997). Fossils, genes and the evolution of animal limbs. Nature (London) 388: 639-648.

Simpson P, Berreur P, Berreur-Bonnenfant J (1980). The initiation of pupariation in Drosophila: dependence on growth of the imaginal discs. I Embryol Exp Morphol 57: 155-165.

Stern DL, Emlen DJ (1999). The developmental basis for allometry in insects. Development 126: 1091-1101.

Struhl G, Basler K (1993). Organizing activity of wingless protein in Drosophila. Cell 72: 527-540.

Svacha P (1992). What are and what are not imaginal discs: Reevaluation of some basic concepts (Insecta, Holometabola). Dev Biol 154: 101-117.

Truman JW, Riddiford LM (2002). Endocrine insights into the evolution of metamorphosis in insects. Annu Rev Entomol 47: 467-500.

Weihe U, Milán M, Cohen SM (2005). Drosophila limb development. Comprehens Mol Insect Sci 305-347 (Chapter 1.9).

Weinkove D, Leevers S (2000). The genetic control of organ growth: Insights from Drosophila. Curr Opin Genet Dev 10: 75-80.

Weinkove D, Neufeld TP, Twardzik T, Waterfield MD, Leevers SJ (1999). Regulation of imaginal disc cell size, cell number and organ size by Drosophila class I(A) phosphoinositide 3-kinase and its adaptor. Curr Biol 9: 1019-1029.

West-Eberhard M-J (2003). Developmental Plasticity and Evolution. Oxford University Press: New York.

Zecca M, Basler K, Struhl G (1995). Sequential organizing activities of engrailed, hedgehog and decapentaplegic in the Drosophila wing. Development 121: 2265-2278.

Ziani S (1995). Un interesante caso di teratologia simmetrica in Onthophagus (Paleonthophagus) fracticornis (Coleoptera: Scarabaeidae). Bolletino dell'Associazione Romana di Entomologia 49: 3-4. 